\title{
The Value of Early Pregnancy Ultrasound Parameters in Prediction of First-Trimester Outcome
}

\author{
Aseel Najeeb Abed ${ }^{1}$, Yossra Saleh Khudhur ${ }^{2}$ \\ ${ }^{1}$ M.B.Ch.B. HD.G.O, Salahadeen Health Directorate, Tikrit, Iraq, \\ ${ }^{2}$ Assist. Prof., Obstetrics \& Gynecology. College of Medicine- Tikrit University, Iraq
}

\begin{abstract}
Background: In early pregnancy, it is essential to emphasize viability, and gestational age precisely. Researchers have tried to discover some useful sonographic indicators in early pregnancy so as to expect the outcome of the ongoing pregnancy. The aim of this study is to assess first-trimester ultrasound measurements for the prediction of early pregnancy loss.
\end{abstract}

Subjects and Method: A prospective observational cohort study done in Tikrit city in outpatient clinic of obstetrics and gynecology department in Salah Al-Deen General Hospital from

$1^{\text {st }}$ February-31 ${ }^{\text {st }}$ August 2020. A random sample of 78 pregnant women selected, 8 were lost to follow up. The data collection done through a designed questionnaire, physical examination and transvaginal sonography assessment. Sonography assessment of the crown rump length (CRL), yolk sac (YS) and gestational sac (GS) diameters, \& fetal heart rate (FHR) are recording.

Results: Seventy pregnant women examined by using transvaginal ultrasonography at $6^{\text {th }}, 9^{\text {th }}$ and $12^{\text {th }}$ week of gestation. The readings at 6th week of gestation for the (GSD, YSD, CRL, and FHR) were (14.5 \pm 1.3 ), (3.2 \pm 1.8$),(3.1 \pm 0.8), \&(105 \pm 10.6)$ respectively, lower among those with first trimester loss than those continue pregnancy $(26.1 \pm 5.2),(3.9 \pm 0.3),(5.1 \pm 0.5)$, and $(119 \pm 3)$. The readings at 12 th week of gestation for the (GSD, YSD, CRL, and FHR) were as follows; [(25.1 \pm 3.5$),(3.6 \pm 0.3),(13 \pm 2.1) . \&(165 \pm 1)]$ were lower among with first trimester loss group than those continue pregnancy [(59.2 \pm 4.1$),(4.5 \pm 0.7),(50.7 \pm 5.7)$ $\&(171 \pm 5)]$.

Conclusions: The current study found that lower GSD, YSD, CRL, and FHR may indicate early pregnancy loss.

Keywords: Early pregnancy loss, crown rump length, yolk sac, gestational sac diameters, fetal heart rate.

\section{Introduction}

Spontaneous abortion is specified to end a pregnancy without medical or mechanical means before a fetus is sufficiently established to be able to survive. In other words, its fetus loss before the twenty week of gestation. ${ }^{[1]}$ spontaneous miscarriage may be the outcome in $15 \%$ of confirmed pregnancies. The recurrent loss is confirmed if loss occure in $\geq 3$ pregnancies, with prevalence of $2 \%$ of pregnancies. ${ }^{[2]}$ Ultrasonography has an important function in defining the proceeding of pregnancy and foreseeing outcome. 1st trimester of pregnancy is known as twelve weeks next to the last menstrual period is now a method of predicting an abnormal fetal outcome in both cases where a live embryo is present and even before visualization of the embryo itself. [3] With continuous technological achievements; high-frequency transvaginal scanning, have permitted the resolution of ultrasound imaging in the 1 st trimester to develop to a level at which early fetal development can be estimated and watched in detail. ${ }^{[4]}$ Ultrasonography is a safe method because it does use too low power levels and not use ionizing radiation, so not cause adverse heating or pressure effects in tissue. Generally Ultrasonography advantages to patients outweigh the risks. ${ }^{[5]}$ Researchers have tried to discover some useful sonographic indicators in early pregnancy so as to expect the outcome of the 
ongoing pregnancy. These are as follows; gestational sac diameter (GSD), yolk sac diameter (YSD), crown-rump length (CRL), and fetal heart rate (FHR). ${ }^{[6]}$ CRL gives a more precise assessment of gestational age because GSD shows higher variability of prediction of age. ${ }^{[7]}$ In early pregnancy, it is essential to emphasize viability, set up gestational age precisely, and define the number of fetuses and, in the case of multiple pregnancies, estimate amnionicity \& chorionicity. ${ }^{[4]}$ This study was conducted to assess first-trimester ultrasound measurements role for the prediction of early pregnancy loss

\section{Subjects and Method}

This is a prospective observational cohort study done in Tikrit city in outpatient clinic of obstetrics and gynecology department of Salah Al-Deen General Hospital from $1^{\text {st }}$ February-31 $1^{\text {st }}$ August 2020. Study carried out on a convenient, randomly selected sample of 78 pregnant women who were attendants this hospital. Inclusion Criteria include mothers at any age, any parity, singleton pregnancy, 1 st trimester pregnancy (6-8 weeks) with a reliable date. The mothers with chronic medical disorders (heart disease, DM, chronic hypertension, renal diseases, etc.), multiple pregnancies, smokers, and drug abusers, known uterine abnormalities, uncertain gestational age, and extra uterine pregnancy were excluded from the study. The data collection tools included designed closed and open-ended questionnaire, by using direct interviewing, physical examination by the researcher and transvaginal sonography assessment. The information collected through the questionnaire related to: Demographic questions, (e.g age, sex, residence), and questions related to obstetrical and gynecological history, previous medical history. Physical Examination was done for the mothers in order to assess the general condition, abdominal and local examinations, and gestational age calculation according to modified Naegele's rule. Routine investigations (CBC, ABO and $\mathrm{Rh}$ typing, urine analysis, RBS also was done for each mother. Sonography assessment using 2 Dimensions transvaginal ultrasound imaging, the crown rump length (CRL), yolk sac (YS) and gestational sac (GS) diameters, $\&$ fetal heart rate (FHR) are recording. Then follow up them at 9 and 12 weeks gestational age to record the result of pregnancy.

\section{Results}

This study was carried out on 78 pregnant women examined by using transvaginal ultrasonography starting early in the first trimester with a first scan between 6 8 weeks. A follow up scan was conducted at 9 weeks and at 12 weeks. During follow up 8 was lost due to the condition of COVID19 pandemic, therefore outcome of first trimester of the 70 pregnancies were recorded. For the 70 pregnant women followed $6(9 \%)$ had early pregnancy loss, and 64(91\%) continue pregnancy after 12 weeks.

Table 1. The General Characteristics of the Patient in Study

\begin{tabular}{|c|c|c|}
\hline Age & No. & Percent \\
\hline$\leq 20$ & 13 & 16.7 \\
\hline $21-35$ & 59 & 75.6 \\
\hline$>35$ & 6 & 7.7 \\
\hline Total & $\mathbf{7 8}$ & $\mathbf{1 0 0 . 0}$ \\
\hline BMI & $27.5 \pm 4.2$ & BMI \\
\hline HB & $11.5 \pm 2.3$ & HB \\
\hline \multicolumn{3}{|c|}{ Gravida } \\
\hline 1 & 14 & 17.9 \\
\hline $2 \_3$ & 45 & 57.7 \\
\hline$>3$ & 19 & 24.4 \\
\hline Total & $\mathbf{7 8}$ & $\mathbf{1 0 0 . 0}$ \\
\hline
\end{tabular}

The gestational sac diameter at 6 wk of gestation (14.5 \pm 1.3$)$ was lower among with first trimester loss group than those continue pregnancy $(26.1 \pm 5.2)$, this relation was statistically significant, as shown in table 2. The gestational sac diameter at 9 wk of gestation (28.1 \pm 3.3$)$ was lower among with first trimester loss group than those continue pregnancy $(37.8 \pm 2.5)$, this relation was statistically significant, as shown in table 2. The gestational sac diameter at 12 week of gestation $(25.1 \pm 3.5)$ was lower among with first trimester loss group than those continue pregnancy $(59.2 \pm 4.1)$, this relation was statistically significant, as shown in table 2 
Table 2: Relation between Gestational Sac Diameter at Different Gestational Age Period and Pregnancy Outcome

\begin{tabular}{|c|c|c|c|c|c|}
\hline \multirow{2}{*}{$\begin{array}{l}\text { Gestational sac } \\
\text { diameter (mm) }\end{array}$} & \multicolumn{2}{|c|}{ First trimester loss } & \multicolumn{2}{|c|}{ Continuing pregnancy } & \multirow{2}{*}{ P value } \\
\hline & Mean \pm SD & Rang & Mean \pm SD & Rang & \\
\hline $6 \mathrm{wk}$ & $14.5 \pm 1.3$ & $12-23$ & $26.1 \pm 5.2$ & $13-35$ & $<0.05 \mathrm{~S}$ \\
\hline 9 wk & $28.1 \pm 3.3$ & $21-33$ & $37.8 \pm 2.5$ & $35-43$ & $<0.05 \mathrm{~S}$ \\
\hline $12 \mathrm{wk}$ & $25.1 \pm 3.5$ & $21-27$ & $59.2 \pm 4.1$ & $52-64$ & $<0.05 \mathrm{~S}$ \\
\hline
\end{tabular}

The Yolk sac diameter at $6 \mathrm{wk}$ of gestation was lower among with first trimester loss group (3.2 \pm 1.8$)$ than those continue pregnancy (3.9 \pm 0.3$)$, this relation was statistically not significant, as shown in table 3 . The Yolk sac diameter at 9 wk of gestation was lower among with first trimester loss group $(5.3 \pm 0.9)$ than those continue pregnancy $(5.8 \pm 0.6)$, this relation was statistically significant, as shown in table 3. The Yolk sac diameter at 12 wk of gestation was lower among with first trimester loss group (3.6 \pm 0.3$)$ than those continue pregnancy $(4.5 \pm 0.7)$, this relation was statistically not significant, There were lower steady increase in yolk sac diameter then decrease after 9 wk of gestation among the group with early pregnancy loss than the continuing pregnancy group, as shown in table 3 .

Table 3: Relation between Yolk Sac at Different Gestational Age Period and Pregnancy Outcome

\begin{tabular}{|c|c|c|c|c|c|}
\hline \multirow{2}{*}{$\begin{array}{l}\text { Yolk sac diameter } \\
(\mathbf{m m})\end{array}$} & \multicolumn{2}{|c|}{ First trimester loss } & \multicolumn{2}{|c|}{ Continuing pregnancy } & \multirow{2}{*}{$P$ value } \\
\hline & Mean \pm SD & Rang & Mean \pm SD & Rang & \\
\hline $6 \mathrm{wk}$ & $3.2 \pm 1.8$ & $2.5-7$ & $3.9 \pm 0.3$ & $3.4-6.5$ & $>0.05 \mathrm{NS}$ \\
\hline $9 \mathrm{wk}$ & $5.3 \pm 0.9$ & $4.6-7.1$ & $5.8 \pm 0.6$ & $5.1-6.8$ & $<0.05 \mathrm{~S}$ \\
\hline $12 \mathrm{wk}$ & $3.6 \pm 0.3$ & $3.2-4.1$ & $4.5 \pm 0.7$ & $3.2-5.5$ & $>0.05 \mathrm{NS}$ \\
\hline
\end{tabular}

The crown-rump length (CRL) at 6 wk of gestation was lower among with first trimester loss group (3.1 \pm 0.8$)$ than those continue pregnancy $(5.1 \pm 0.5)$, this relation was statistically not significant, as shown in table 4. The CRL at 9 wk of gestation was lower among with first trimester loss group $(17.5 \pm 6.7)$ than those continue pregnancy (27.8 \pm 3.6$)$, this relation was statistically significant, as shown in table 4 . The CRL at $12 \mathrm{wk}$ of gestation was lower among with first trimester loss group $(13 \pm 2.1)$ than those continue pregnancy (50.7 \pm 5.7$)$, this relation was statistically not significant, as shown in table 4.

Table 4: Relation between Gestational Crown-Rump Length (CRL) At Different Gestational Age Period and Pregnancy Outcome

\begin{tabular}{|l|c|c|c|c|c|}
\hline \multirow{2}{*}{$\begin{array}{l}\text { Crown-rump } \\
\text { length (CRL) mm }\end{array}$} & \multicolumn{2}{|c|}{ First trimester loss } & \multicolumn{2}{c|}{ Continuing pregnancy } & \multirow{2}{*}{ P value } \\
\cline { 2 - 6 } & Mean \pm SD & Rang & Mean \pm SD & $4.2-6.3$ & $<0.05 \mathrm{~S}$ \\
\hline $6 \mathrm{wk}$ & $3.1 \pm 0.8$ & $2.3-4.2$ & $5.1 \pm 0.5$ & $23-30$ & $<0.05 \mathrm{~S}$ \\
\hline $9 \mathrm{wk}$ & $17.5 \pm 6.7$ & $10-23$ & $27.8 \pm 3.6$ & $53-65$ & $<0.05 \mathrm{~S}$ \\
\hline $12 \mathrm{wk}$ & $13 \pm 2.1$ & $29-35$ & $50.7 \pm 5.7$ & & \\
\hline
\end{tabular}


The Fetal heart rate (FHR) at 6 wk of gestation was lower among with first trimester loss group $(105 \pm 10.6)$ than those continue pregnancy $(119 \pm 3)$, this relation was statistically significant, as shown in table 5 . The FHR at 9 wk of gestation was lower among with first trimester loss group (162 \pm 9 ) than those continue pregnancy
$(170 \pm 4)$, this relation was statistically not significant, as shown in table 5. The FHR at 12 wk of gestation was lower among with first trimester loss group (165 \pm 1$)$ than those continue pregnancy $(171 \pm 5)$, this relation was statistically significant, as shown in table 5 .

Table 5: Relation between Gestational Fetal Heart Rate (FHR) At Different Gestational Age and Pregnancy Outcome

\begin{tabular}{|l|c|c|c|c|c|}
\hline \multirow{2}{*}{ FHR (BPM) } & \multicolumn{2}{|c|}{ First trimester loss } & \multicolumn{2}{c|}{ Continuing pregnancy } & \multirow{2}{*}{ P value } \\
\cline { 2 - 5 } & Mean \pm SD & Rang & Mean \pm SD & Rang & \\
\hline $6 \mathrm{wk}$ & $105 \pm 10.6$ & $98-126$ & $119 \pm 3$ & $110-126$ & $<0.05 \mathrm{~S}$ \\
\hline $9 \mathrm{wk}$ & $162 \pm 9$ & $159-170$ & $170 \pm 4$ & $164-177$ & $>0.05 \mathrm{~S}$ \\
\hline $12 \mathrm{wk}$ & $165 \pm 1$ & $165-166$ & $171 \pm 5$ & $162-173$ & $<0.05 \mathrm{~S}$ \\
\hline
\end{tabular}

\section{Discussion}

The early identification of pregnancies at increased risk for early loss is important issue for health personnel and for the mother herself. The current study revealed that readings of GSD at $6^{\text {th }}$ week of gestation $(14.5 \pm 1.3)$ was lower among with first trimester loss group than those continue pregnancy $(26.1 \pm 5.2)$ GSD at $9^{\text {th }}$ week of (28.1 \pm 3.3$)$ was lower among with first trimester loss group than those continue pregnancy (37.8 \pm 2.5$)$ GSD at $12^{\text {th }}$ week of gestation $(25.1 \pm 3.5)$ was lower among with first trimester loss group than those continue pregnancy (59.2 \pm 4.1$)$. This agrees with Al Darwish AG et al who found that GSD below normal $\left(<10^{\text {th }}\right.$ percentile) was associated significantly with PTL (preterm Labor), $1^{\text {st }} \& 2^{\text {nd }}$ mid-trimester abortions. ${ }^{[8]}$ This agrees with Al Darwish AG et al who found that abnormal CRL $\left(<10^{\text {th }}\right.$ percentile),$>90^{\text {th }}$ percentile) was associated significantly with $1^{\text {st }}$ trimester abortion and intrauterine fetal death (IUFD). ${ }^{[8]}$ This agrees with Al Darwish AG et al who found that Y.S less than normal $\left(<10^{\text {th }}\right.$ percentile) was associated significantly with PROM and $1^{\text {st }}$ trimester abortion. ${ }^{[8]}$ This agrees with Al Darwish AG et al who found that abnormal GS measurements significantly related to abortion, CRL is considered an important predictor for $1^{\text {st }} \& 2^{\text {nd }}$ trimester abortion and intrauterine fetal death IUFD, abnormal YSD strongly related to $1^{\text {st }}$ trimester abortion, $\mathrm{PROM}$ and $\mathrm{APH}$. ${ }^{[8]}$ The current study results were in agreement with Christiansen et al., $2017^{[9]}$ they found that pregnancies that will end in abortion after 6 weeks' gestation may be predicted by the measures of YS and GS. Additionally, they determined that abortion is predicted at least 7-days prior to occurrence. The other parameters also became abnormal prior to spontaneous abortion, but at a later time in pregnancy and closer to the event. [9] Also similar to the current study results, Odeh et al, 2009 compare gestational sac volume (GSV) between normal pregnancies, missed abortion and anembryonic pregnancies they found that GSV in missed abortion and anembryonic pregnancies are considerably smaller than normal pregnancies, starting at 7-weeks of gestational age. ${ }^{[10]}$ Also results of Batmaz et al, 2016 in their research agreed with the current study, they found that GS readings can help to distinguish between normal and abnormal pregnancies. ${ }^{[11]}$ Also Jauniaux et al 2005 proved that in pregnancies with a live fetus at 6-10-weeks' gestation the rate of subsequent fetal loss is associated to maternal age, and the ultrasound findings of small GSD and fetal bradycardia (FHR bradycardia), relative to CRL. ${ }^{[12]}$ Also, the current research is in accordance with many other researches as Balsane et al, ${ }^{[13]} 2017$, Agarwal et al, ${ }^{[14]} 2017$ and Abu Elghar et al, ${ }^{[15]} 2013$, S Abdulkadhim et al, ${ }^{[16]} 2017$ found that with majority of patients with embryonic heart rate $<100$ BPM ended up with poor outcome. Regarding the FHR, Most of the patients who had poor first trimester outcome had EHR below 100 BPM. This finding came in agreement with those of Doubilet et al $1995^{[17]}$ who found that an FER below 90 beats per minute at 6-8 weeks of gestation have been found to be related with a high probability of subsequent $1^{\text {st }}$ trimester demise. Another similar research by Benson et al $2013^{[18]}$ identify the survival rate according to the FHR in 6.3-7 gestational weeks to 
be nearly $52 \%$ when the FHR between $100-119$ bpm and this drop to $0 \%$ when the heart rate drop to less than $100 \mathrm{bpm}$. The current study revealed that YSD at $6^{\text {th }}$ week of gestation was lower among with first trimester loss group (3.2 \pm 1.8$)$ than those continue pregnancy $(3.9 \pm 0.3)$, YSD at $9^{\text {th }}$ week of gestation was lower among with first trimester loss group (5.3 \pm 0.9$)$ than those continue pregnancy (5.8 \pm 0.6$)$, and YSD at $12^{\text {th }}$ week of gestation was lower among with first trimester loss group (3.6 \pm 0.3$)$ than those continue pregnancy (4.5 \pm 0.7$)$. This result disagrees with a research by Cho FN et al $2006^{[19]}$ shown that the largest acceptable size of yolk sac was $8.1 \mathrm{~mm}$, and that the quality of the yolk sac is also an important predictor of the outcome of pregnancy. The poor quality and early regression of a yolk sac are more specific than the large size of a yolk sac in predicting pregnancy loss. According to SinanTan et al $^{[20]} 2012$, evaluation of yolk sac should be part of a full $1^{\text {st }}$ trimester sonographic examination as an abnormality in the sonographic appearance of a yolk sac can predict subsequent embryonic death. Another study made by Asim $\mathrm{K}$ et al, ${ }^{[21]}$ gave the criteria of subsequent first trimester demise depending on the quality of the yolk sac as 1-Absence of the yolk sac, 2-Too large yolk sac more than $6 \mathrm{~mm}$ (sensitivity $16 \%$, specificity $97 \%$ ), and 3-Too small yolk sac less than $3 \mathrm{~mm}$ (sensitivity $15 \%$, specificity $95 \%$ ). In the current study the $3^{\text {rd }}$ point was found to have bad impact on the pregnancy outcome.

\section{Conclusions}

The readings at $6^{\text {th }}, 9^{\text {th }}$ and $12^{\text {th }}$ week of gestation for the (GSD, YSD, CRL, and FHR) were lower among with first trimester loss group than those continue pregnancy. The current study found that that those with early pregnancy loss the mean GSD, YSD, CRL, and FHR were lower than the value among those continue pregnancy. This study proves the function of early ultrasound in predicting abnormal outcomes of pregnancy it could be useful to obstetricians to anticipate adverse outcomes and being warned to manage prenatal care and delivery more accurately. Early fetal ultrasound should be used as a tool to predict pregnancy outcome so as to manage prenatal care and delivery more efficiently.

Financial Disclosure: There is no financial
disclosure.

Conflict of Interest: None to declare.

Ethical Clearance: All experimental protocols were approved under the Salahadeen Health Directorate and all experiments were carried out in accordance with approved guidelines.

\section{References}

1. Li L, Leung PC, Chung TK. Systematic review of Chinese medicine for miscarriage during early pregnancy. Evid Based Complement Altern Med. 2014; 2014:753856.

2. Ford HB, Schust DJ. Recurrent pregnancy loss: etiology, diagnosis, and therapy. Rev Obstet Gynecol. 2009; 2(2):76-83.

3. Kratochwil E, Eisenhut L. Der fruheste nachweis der fatalen herzaction durch ultrascall. Geburtshilfe Frauenheilkd 1967; 27: 176-180.

4. ISUOG Practice Guidelines: performance of firsttrimester fetal ultrasound scan. Ultrasound Obstet Gynecol.2013; 41: 102-113.

5. Jauniaux E, Gulbis B. Fluid compartments of the embryonic environment. Hum Reprod Update 2000; 6: 268-278.

6. Jauniaux E, Gulbis B. In vivo investigation of placental transfer early in human pregnancy. Eur $\mathrm{J}$ Obstet Gynecol Reprod Biol 2000; 92: 45-49.

7. Ziskin MC. Basic physics of ultrasound. In: The Principles and Practice of Ultrasonography in Obstetrics and Gynecology, 4th ed, Fleischer AC, Romero R, Manning FA, et al (eds), Appleton \& Lange, Norwalk, CT 1991.

8. Al Darwish AG. Early Ultrasound Fetal Parameters as a Predictor for Pregnancy Outcome: A Prospective Observational Cohort Study. Gynecology and Obstetrics Open Access Open Journal Research 2019; 1(1): 7-12.

9. Christiansena M, et al. Prediction of first trimester miscarriage by ultrasound. Fertility and Sterility. 2017; 108(3): e383-e384.

10. Odeh M, Tendler R, Kais M. OP06. 04: Gestational sac volume in missed abortion compared to normal pregnancies. Ultrasound in Obstetrics \& Gynecology. 2009; 34(S1): 79-80.

11. Batmaz G, Aksoy A, Aydin S, Ozcan P, Dane C, Dane $\mathrm{B}$. The early pregnancy volume measurements in predicting pregnancy outcome. Clin Exp Obstet Gynecol. 2016; 43(2): 241-244.

12. Jauniaux E, Johns J, Burton GJ. The role of ultrasound imaging in diagnosing and investigating early pregnancy failure. Ultrasound Obstet Gynecol. 2005; 25(6):613-624. 
13. Balsane R, Vyas J, Rajoria L, Agarwal P, Gupta S. To study the association between initial fetal crown-rump length and subsequent abortion in a viable first trimester pregnancy. International Journal of Reproduction, Contraception, Obstetrics and Gynecology. 2017; 5(6): 1744-1747.

14. Agarwal N, Sharma A. Miscarriage and early first trimester growth restriction by ultrasound. International Journal of Reproduction, Contraception, Obstetrics and Gynecology. 2017; 5(5): 1558-1561.

15. Abuelghar WM, Fathi HM, Ellaithy MI, Anwar MA. Can a smaller than expected crown-rump length reliably predict the occurrence of subsequent miscarriage in a viable first trimester pregnancy? J Obstet Gynaecol Res. 2013; 39(10): 1449-1455.

16. Abdulkadhim $\mathrm{S}$ et al. Predictors of poor first trimester outcome in asymptomatic women: the value of embryonic heart rate, mid sac diameter/ yolk sac ratio \& mid sac diameter/crown rump length. Al-Kindy College Medical Journal 2017:13 (2):46-50.

17. Doubilet PM. Ultrasound Evaluation of the First Trimester. Radiol. Clin. North Am. 2014; 52 (6): 1191-1199

18. Benson CB, Doubilet PM, Peters HE, et al. Intrauterine fluid with ectopic pregnancy: a reappraisal. J Ultrasound Med 2013; 32: 389-93.

19. Cho FN, Chen SN, Tai MH, Yang TL. The quality and size of yolk sac in early pregnancy loss. Aust N Z J Obstet Gynaeco. 2006; 46(5):413-8. 138-21 Sinan Tan .Sonographic evaluation of the yolk sac .journal of ultrasound in medicine, 2012; 31: 87-95

20. Sinan Tan .Sonographic evaluation of the yolk sac .journal of ultrasound in medicine 2012; 31:87-95

21. Asim K, Sanja K, Jose MC, Badreldeen A. Ultrasound evaluation of the abnormal early pregnancy. Donald School journal of ultrasound in obstetrics \& gynecology 2008; 2(2):87-105. 